\title{
Physical Society's Exhibition of Scientific Instruments and Apparatus
}

$\mathrm{T}$ HE Physical Society's twenty-fifth annual Exhibition of Scientific Instruments and Apparatus was held at the Imperial College of Science and Technology on January 1-3. It is interesting to recall that the first exhibition organised by the Society was held in the same College in 1905, and, except for the War period, it has been an annual event of outstanding importance in the scientific world. Perhaps it is not too much to say that it provides the regular milestones for British scientific instrument manufacturers, much in the same way that the annual motor show does for the automobile industry.

In 1920 the Optical Society joined the Physical Society of London at these exhibitions, and in 1932 these two bodies amalgamated under the title of "The Physical Society". The first exhibition was open for one evening only and there were $17 \mathrm{ex}$ hibitors, nearly all of whom are numbered among the 110 organisations that took part in this year's exhibition. In 1926 the Research and Experimental Section was added; it was divided into three groups. The first, Group A, was intended to show "typical results of recent physical research of general interest and examples of new and improved laboratory methods"; the second, Group B, was to include "little known and effective lecture experiments of interest to teachers of physics"; while the third, Group C, was to provide an "opportunity for demonstrating repetitions of famous historical experiments in physics". This last group was discontinued in 1931.

Largely at the instigation of the exhibitors themselves in general meeting, an annual competition in craftsmanship and draughtsmanship for apprentices and learners employed by exhibiting firms is now organised in connexion with each exhibition, and money prizes to the value of over $£ 40$, as well as certificates of honourable mention, are awarded each year. The work submitted is exhibited in a special section. Mr. R. W. Paul, who has done so mueh to establish these competitions, writing in the February 1934 issue of the Journal of Scientific Instruments, says : "At present the principals of some of our leading concerns appear to take no active steps to encourage their apprentices to compete in the Craftsmanship Competition, so that the interest taken in the workshops varies greatly. Obviously the provision of facilities for executing the simple job which suffices to show an apprentice's skill involves some altruism on the part of a firm for the benefit of the industry, but regard should be had to the beneficial effect on the workers of the spirit of emulation aroused and the good effect on the morale of the shops. The stimulus given by the competition to candidates is known in many cases to have had a beneficial effect on their careers. Further, it is believed the competition does something to raise the international status of our instrument trade."

The problem of providing the ever-increasing accommodation and supplies of electrical power necessary is one which, for the past few years, has taxed the ingenuity of those responsible. But with the valuable help of the College authorities and the co-operation of the exhibitors, it has been possible to arrange matters satisfactorily, although perhaps not ideally. It must be remembered, however, that the Society receives the great privilege of free accom- modation in the College, often at considerable inconvenience to the academic and research staffs. No charge is made to exhibitors for their stands, who only participate at the invitation of the Society, and it is this feature among others which makes these exhibitions so different from the ordinary trade exhibitions. Another noteworthy feature is that, in a very large number of instances, the directors and leading technical experts of the firms exhibiting are in attendance on the stands, so that competent replies are received to those highly technical questions which those genuinely interested must of necessity ask.

The catalogue is now issued about a fortnight before the exhibition opens, and it is valuable as a handbook to be kept on the desk until the next issue appears. Most exhibitors give a brief description of the principles underlying the action of the instruments and it is this that renders the catalogue so helpful. A limited number of copies is still available and may be obtained from the office of the Society at the Institute of Physics, 1 Lowther Gardens, South Kensington, S.W.7. (1s. post free).

The Committee of the Society responsible for the organisation of these exhibitions strongly endorses the view of the Institute of Physics that it is desirable that firms and research organisations taking part in exhibitions organised by scientific societies should include the names of individuals associated with each of the exhibits. The entries in the catalogue for the past few years have displayed a desirable improvement in this respect, and credit is usually given to the designer and others responsible for the develop. ment of the various individual exhibits.

Among the devices in the trade section this year were many examples of recent developments and improvements in electrical indicating instruments, galvanometers, radio instruments, relays, pyrometers, thermostats, humidity measuring apparatus, meteorological instruments, microscopes, projection and cinema apparatus, in addition to recorders, controllers and meters for numerous purposes. Representative collections of new technical books and journals were also shown. The recent rapid development of acoustics was represented by several exhibits, and the number of new illumination meters and applications of rectifiers which were shown was worthy of note. In the limited space available here it is impossible to mention individual exhibits shown in the trade section, so many of which appeared to be of special interest and importance. Descriptions of the exhibits may be found in the various trade journals, in the catalogue of the exhibition, and in the February issue of the Journal of Scientific Instru. ments, which is devoted each year to accounts of the most important new devices shown in the various sections; summaries of the discourses will also be included in that issue of the Journal. We must be content here with brief reference to a few typical exhibits, which are mentioned for no other reason than to indicate the wide variety of instruments and apparatus shown. These are : an apparatus intended for the detection of cracks in iron or steel by local magnetisation; a device for determining the ripeness of fresh tomato juice; an electrical instrument for determining whether hunting by scent on any particular day is likely to be satisfactory ; a special red 
light without heat for stimulating plant growth; and, of course, numerous examples of more ordinary instruments in new and improved designs.

The Research and Experimental Section provides always a fascinating display of the research physicists' work before it reaches the commercial production stage. Thirty-one of the research laboratories attached to Government departments, research associations, universities and manufacturing firms exhibited. Many of the devices shown had been developed for testing the properties and behaviour of a wide variety of materials under the differing conditions met with in practice, whilst several others were concerned with applications of cathode ray tubes and electron cameras to all manner of problems. One exhibit was staged to demonstrate the possibilities of ordering a number of different materials to match a given colour by quoting a standard name, number or code word, and another was designed for the routine measurement of the colour values of fabric and similar surfaces viewed by diffusely reflected light. Developments in the method of controlling the speed of small electric and mechanical motions by means of light tuning forks formed the subject of another exhibit. Others were, a galvano. meter which is said to be immune from mechanical disturbance of the zero, despite violent pitching and. rolling of the type met with in marine work, and a high speed motion picture timing system and camera which is said to take as many as 2,500 pictures a second.

Radio and telephony formed the subject of several important exhibits in the Research Section, and among these mention may be made of a standard receiver for the measurement of radio interference, a map of England and southern Scotland showing the electrical resistivity of the earth, and an 'artificial mouth' for testing telephones.

The growing use of discharge tubes for illumination purposes has led to the development of various devices for studying their behaviour, and some of these were exhibited. Another illumination device shown was a gas burner for producing an intermittent flame or light.

On each evening of the exhibition a discourse was delivered. The first was entitled "The Architecture of Molecules" in which Dr. B. Wheeler Robinson gave an account of recent $X$-ray investigations of molecular structure made at the Davy-Faraday Laboratory and elsewhere; the second was delivered by Dr. C. V. Drysdale on "The Problem of Ether Drift", a subject which readers of NATURE will know he has recently taken up with characteristic zeal; and on the third day, when the public is admitted to the Exhibition, the Astronomer Royal spoke on "Giant Telescopes".

The attendance at this year's Exhibition is not yet known, but in the past two years it has wanted but a few hundreds to be ten thousand. The Society is justly proud of the record of service it has rendered for so long to all those concerned with instruments, to the instrument industry in Great Britain, and to the public.

Herbert R. Lang.

\section{Biochemistry of Marine Phytoplankton}

A SERIES of papers on "Observations on the A Fatty Constituents of Marine Plankton" (J.Exp. Biol., 11, 173-197, 198-202, 203-209 ; 1934) sheds considerable light on the content of fat and vitamins $A$ and $D$ in plankton, on which all marine animal life is dependent directly or indirectly for existence.

In Part 1, on the "Biology of the Plankton" by E. R. Gunther, in order to convey a more precise idea of the relative importance of each species, an attempt is made to translate by means of suitable measurements the figures representing the numbers of a species present in a given quantity of plankton into figures representing the volume occupied by that species. The oil content of May phytoplankton from near the Isle of Man was about 6.9 per cent on the dry weight, and it is suggested that the oil content may vary with the species and fluctuate during the life-history. The oil content of July zooplankton varied between 15 and $19 \cdot 3$ per cent. In plankton giving a high oil yield, Calanus finmarchicus was very prominent.

In Part 2, on the "General Character of the Plankton Oils", G. Collin, J. C. Drummond, T. P. Hilditch and E. R. Gunther show that the fatty acid fraction of the zooplankton oils resembled that from fish liver oils. In the non-saponifiable fraction they demonstrated the presence of cholesterol, cetyl and eicoseneyl alcohols, a hydrocarbon suggestive of squalene and possibly batyl alcohol.

In Part 3, on "The Vitamin A and D Content of Oils derived from Plankton", J. C. Drummond and E. R. Gunther describe the results of an examination of the oils by feeding tests, with antimony trichloride and spectroscopically. They show that the phytoplankton oil is more potent than the zooplankton oil in its growth-promoting action, and this is correlated with a greater richness in lipochrome pigments related to carotene. Vitamin $\mathbf{A}$ as such is apparently absent from both phytoplankton and zooplankton. In testing for vitamin $\mathrm{D}$, the degree of healing was determined both by histological (line test) and by X-ray examinations. In daily doses of $50 \mathrm{mgm}$., phytoplankton oil showed no antirachitic activity but zooplankton showed slight activity. It is suggested that the small amount of vitamin D present in the animals results from their irradiation while in surface waters rather than from a prolonged diet of phytoplankton.

\section{Building in Earthquake Countries}

$\mathrm{W}^{\mathrm{s}}$ have received from Dr. C. E. Adams, Dominion astronomer and seismologist in New Zealand, several papers by Mr. R. W. de Montalk. In these, the author, who is an architect, describes a foundation, called the 'Salvus' foundation, that he has devised in order to lessen the effects of destructive earthquakes. It consists of a platform fixed to the ground. This is made of reinforced concrete, the under side of which may be strengthened, if necessary. Round the edge of the platform rises a rim of the same material, which contains a layer of clean fine shingle, 4-11 in. in depth according to the weight 